\title{
Grazing resistance in phytoplankton
}

\author{
Miquel Lürling (10
}

Received: 10 February 2020/Revised: 23 July 2020/Accepted: 28 July 2020/Published online: 11 August 2020

(C) The Author(s) 2020

\begin{abstract}
Phytoplankton is confronted with a variable assemblage of zooplankton grazers that create a strong selection pressure for traits that reduce mortality. Phytoplankton is, however, also challenged to remain suspended and to acquire sufficient resources for growth. Consequently, phytoplanktic organisms have evolved a variety of strategies to survive in a variable environment. An overview is presented of the various phytoplankton defense strategies, and costs and benefits of phytoplankton defenses with a zooming in on grazer-induced colony formation. The tradeoff between phytoplankton competitive abilities and defenses against grazing favor adaptive trait changes-rapid evolution and phenotypic plasticity-that have the potential to influence population and community dynamics, as exemplified by
\end{abstract}

Guest editors: Judit Padisák, J. Alex Elliott, Martin T. Dokulil \& Luigi Naselli-Flores / New, old and evergreen frontiers in freshwater phytoplankton ecology: the legacy of Colin S. Reynolds

\section{Lürling}

Aquatic Ecology \& Water Quality Management Group, Department of Environmental Sciences, Wageningen University, P.O. Box 47, 6700 AA Wageningen, The Netherlands

M. Lürling ( $\square)$

Department of Aquatic Ecology, Netherlands Institute of Ecology (NIOO-KNAW), P.O. Box 50, $6700 \mathrm{AB}$ Wageningen, The Netherlands e-mail: miquel.lurling@wur.nl controlled chemostat experiments. An interspecific defense-growth trade-off could explain seasonal shifts in the species composition of an in situ phytoplankton community yielding defense and growth rate as key traits of the phytoplankton. The importance of grazing and protection against grazing in shaping the phytoplankton community structure should not be underestimated. The trade-offs between nutrient acquisition, remaining suspended, and grazing resistance generate the dynamic phytoplankton community composition.

Keywords Adaptive trait - Algal defense - Antigrazing response $\cdot$ Chemical defense $\cdot$ Induced defense $\cdot$ Morphology $\cdot$ Phenotypic plasticity $\cdot$ Rapid evolution $\cdot$ Trade-off

\section{Introduction}

Phytoplankton can be defined as "the collective of photosynthetic microorganisms, adapted to live partly or continuously in open water" or "planktic photoautotrophs adapted for a life spent wholly or partly in quasi-suspension in open water, and whose powers of motility do not exceed turbulent entrainment" (Reynolds, 2006). The main challenge for photosynthetic plankton is to survive long enough to acquire sufficient energy and nutrients to build new biomass and to reproduce. Consequently, these organisms need to be 
regularly in the upper water strata to collect enough light energy and have a need to "maximize opportunities for suspension" (Reynolds, 2006). Phytoplankton cells also are in demand for nutrients that need to be concentrated from the surrounding water. Smallsized algae with a large surface-to-volume ratio have the most efficient uptake of dissolved nutrients and lowest sinking losses (Reynolds, 2006). Hence, small size might be beneficial for phytoplankton, yet sizes of phytoplankton can span over 9 orders of magnitude from $1 \mu \mathrm{m}^{3}$ in volume for pico-cyanobacteria to around $10^{9} \mu \mathrm{m}^{3}$ for Microcystis colonies (Reynolds, 2006). Water column stability or frequency of its disturbance along with the availability of nutrients formed the basis for explaining large varieties in size and shapes, and seasonal variations in phytoplankton community composition (Reynolds, 1980, 1998). Three adaptive strategies are distinguished in freshwater phytoplankton: (1) high surface-to-volume colonist, small, fast-growing, (C) species; (2) large, low surface-to-volume, slow-growing, nutrient stresstolerant (S) species; (3) light-harvesting, disturbancetolerant ruderal (R) species (Reynolds, 1993; Smayda $\&$ Reynolds, 2001). Such classification suggests that "the physical structure of the environment, or of the availability of nutrients within it,... are, directly or indirectly, the most important variables likely to influence the general composition of the phytoplankton" (Reynolds, 1980). However, survival also means that phytoplankton is challenged to withstand grazing (Reynolds, 2012), which is one of the most important loss processes operating and one of the most powerful forces in phytoplankton selection (Smetacek, 2001).

Phytoplankton is confronted with an assemblage of protozoan and metazoan grazers (Lehman, 1988; Reynolds, 2006), exerting a grazing pressure that varies in time and space, and that can be a steering factor during several periods of the year (Sommer et al., 2012). Investment in adaptations to zooplankton attacks implies phytoplanktic "evolution is ruled by protection and not by competition" (Smetacek, 2001). Hence, grazing creates a strong selection pressure for traits that reduce mortality (Fig. 1). Inasmuch as these traits reduce zooplankton food intake, and therewith affect zooplankton growth and reproduction, they may have variable impacts on plankton dynamics, and, depending on magnitude, may also lead to trophic decoupling (Sommer et al., 2012).

\section{Phytoplankton anti-grazing strategies}

The various phytoplankton anti-grazing strategies can be grouped based on the type of defenses, such as morphological, physiological, and behavioral defenses (Pančić \& Kiørboe, 2018). The review by Pančić \& Kiørboe (2018) provides a detailed overview of the diverse defense mechanisms in phytoplankton. These authors emphasize the need for thorough research on costs and benefits (trade-offs) of the proposed defenses (Pančić \& Kiørboe, 2018). Alternatively, phytoplankton defenses not necessarily need to be classified as phytoplankton traits (morphological, physiological, behavioral), but can also be grouped as strategies along the effects these traits exert on the phytoplankton-zooplankton interaction (Fig. 1). One strategy is to avoid ingestion, which can be achieved via adequate timing of recruitment from cysts (Hansson, 1996; Rengefors et al., 1998), migrating to regions with lower grazing pressure (Latta et al., 2009), changes in movements that result in lower encounter rates with grazers (Selander et al., 2011; Harvey \& Menden-Deuer, 2012), growing to sizes beyond the ingestion capacity of most grazers (Lürling, 2003a), production of grazer deterrents (Xu \& Kiørboe, 2018), or making thick silicate cell walls that provide protection against grazers that crush cells prior to ingestion (Pančić et al., 2019). Another strategy is to avoid digestion after being ingested (Fig. 1). Viable gut passage might be enabled by thickened cell walls (Van Donk et al., 1997), or embedment in mucous (DeMott et al., 2010). Strongly reducing grazing pressure by killing the most dangerous enemies is another highly effective strategy, particularly against generalist grazers, such as Daphnia (DeMott, 1999; Lürling, 2003b). Alternatively, if phytoplankton growth rate equals or exceeds the community filtration rate, the phytoplankton population will be maintained or may even expand (Reynolds, 1984, 2006). Hence, those species are able to tolerate the zooplankton community grazing pressure.

Phytoplankton species are condemned to living with their enemies, yet not all species possess or express defenses against grazers. Many unicellular species lack any defenses and probably allocate savings from maintaining defenses to growth, which may be a most beneficial strategy in competitive environments (Acevedo-Trejos et al., 2018). Other 


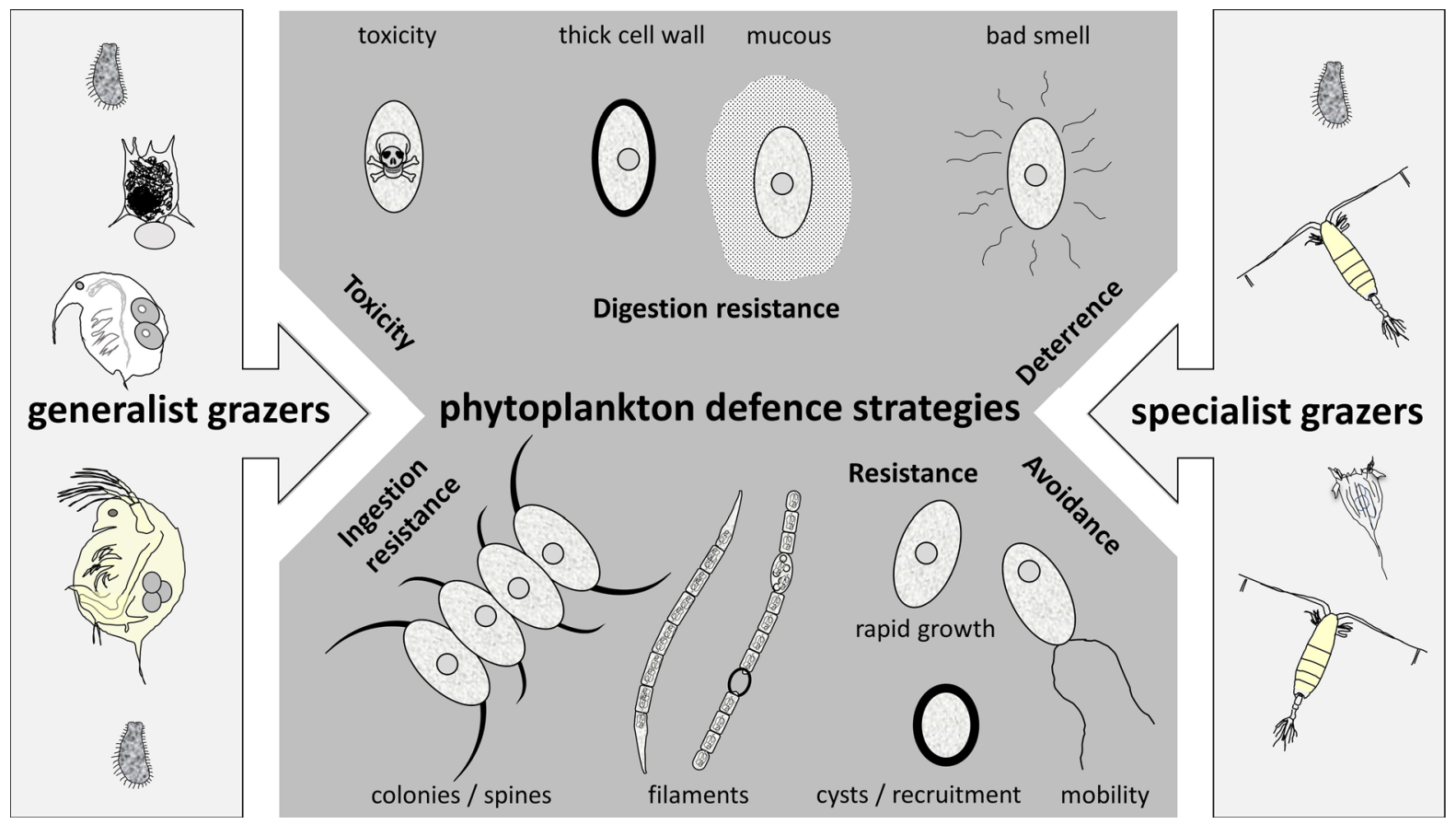

Fig. 1 Potential phytoplankton defenses against generalist and specialist zooplankton grazers. Defenses can be constitutive or inducible and include traits that reduce ingestion by

phytoplankton species may possess constitutive defenses, i.e., they are always expressed, or on an intraspecies-interindividual level, different clones with different traits may be favored depending on environmental factors. The intraspecific genetic diversity within a species allows a rapid adaptive trait change, in which grazing and competition may cause a quick change in the relative abundance of genotypes with different traits, such as competitive ability and defense against grazers (Yamamichi et al., 2011). For instance, exposure to rotifer grazers resulted in rapid evolution in the green alga Chlorella vulgaris Beijerinck that became less nutritious to the rotifers, but also less competitive in comparison with non-grazer exposed clones (Yoshida et al., 2003). The intraspecific genetic diversity is a prerequisite for rapid evolution, a fast, inheritable response (Yamamichi et al., 2011).

Another mechanism of rapid adaptation is inducible defenses, in which a single genotype produces different phenotypes in response to grazing. Induced defenses are typical expressions of phenotypic plasticity, the defenses will only be activated when needed. An overview of inducible defenses is given zooplankton, reduce digestion, reduce the chance of encountering zooplankton, and even those that are directly detrimental to zooplankton

in Van Donk et al. (2011). Inducible defenses are favored when the risk of mortality from grazing is variable and reliable cues are present, as defenses usually come with costs (Tollrian \& Harvell, 1999; Pančić \& Kiørboe, 2018).

\section{Costs and benefits of phytoplankton defenses}

Phytoplankton species (or even clones within a species) have adopted various strategies of coping with the heterogeneity in their environment. In response to grazing, phytoplankton may possess no, induced, or constitutive defenses. Remaining small with a favorable surface-to-volume ratio allows fast growth and lowers sinking loss (Reynolds, 1984). In a competitive, mixed environment small phytoplankton species became dominant, whereas larger species were competitively excluded (Burson et al., 2018). However, undefended, nanoplanktic algae, i.e., algae between 2 and $30 \mu \mathrm{m}$ in length, are a main food source for freshwater zooplankton (Sterner, 1989). There are countless experiments that underpin "the 
fate of these algae is to be grazed" (Reynolds et al., 1982).

Growing to sizes above the ingestion capacity of zooplankton is an effective strategy to protect the cells against grazing (Lehman, 1988). Large size, forming colonies or elongated chains are widespread characteristics among numerous phytoplankton species. For instance, members of the genus Microcystis are among the most commonly found bloom-forming cyanobacteria (Harke et al., 2016) that are predominantly unicellular in the laboratory, but colonial in the field (Xiao et al., 2018). Several abiotic and biotic factors, including grazers, are involved in colony formation, which is mostly achieved through cell division, but in Microcystis colonies may additionally grow through cell adhesion (Xiao et al., 2017, 2018). The typical colonial morphology reduces zooplankton feeding rates (Fulton \& Paerl, 1987, 1988). Microcystis aeruginosa (Kützing) Kützing colonies strongly depressed clearance rates in the flagellate Ochromonas, but at a tax of lower growth and higher sinking rates for colonies (Yang et al., 2009). Likewise, Scenedesmus colonies were far less grazed upon by zooplankton, but also had higher sinking rates than unicells (Lürling, 2003a). A trade-off between grazing loss and sinking loss in Desmodesmus/Scenedesmus has been found-larger, protected Scenedesmaceae had the lowest grazing loss, but the highest sinking loss (Verschoor et al., 2009). Metabolic costs that are associated with (induced) colony formation might be reflected in reduced growth of colonial populations (Zhu et al., 2016; Albini et al., 2019), particularly under resource limitation (Zhu et al., 2016). In diatoms, thick silicate cell walls provide protection against grazers that crush cells prior to ingestion (Pančić et al., 2019). Such thicker silicate cell walls may be induced in the presence of zooplankton grazers (Pondaven et al., 2007), but silica deposition decreased with increasing growth rates pointing to costs associated with the shell thickening (Pančić et al., 2019).

Also filamentous cyanobacteria may hamper ingestion by zooplankton when above critical concentrations (Gliwicz, 1990a, b). Filamentous cyanobacteria might further aggregate into big flakes in the presence of zooplankton (Lynch, 1980), or express thickening and shortening of filaments in the presence of Daphnia, its exudates or the kairomone sodium octyl sulfate that all reduce grazing loss (Cerbin et al., 2013;
Wejnerowski et al., 2018). Cells in filaments may also benefit from $\mathrm{N}_{2}$ fixation in specialized cells. To date, costs of a filamentous morphology have not been assessed.

In contrast to an increase in size, also the opposite of becoming smaller and more defended can be an effective way of reducing grazing loss (Yoshida et al., 2004). Chlorella vulgaris grown with rotifer (Brachionus) grazers were heritably smaller, but competitively inferior relative to cells grown in the absence of rotifers (Yoshida et al., 2003). Food ingestion in Brachionus is steered by particle size, the feeding efficiency curve is bell shaped, which implies that feeding on algae either larger or smaller than the optimal size window will result in reduced feeding efficiency and lower rotifer population growth rates (Rothhaupt, 1990). Follow-up research on the study of Yoshida et al. (2003) revealed that the rotifers did not feed selectively on either the defended or undefended clone, but that the defended clone had far better gut passage survival than the more competitive, undefended clone of $C$. vulgaris (Meyer et al., 2006). Such resistance against digestion has also been observed in green algae with thickened cell walls (Van Donk et al., 1997). Green algae covered by mucilaginous sheaths are also defended against digestion and grazing promotes such digestion defenses at the cost of slower growth (DeMott \& McKinney, 2015).

Whether phytoplankton cells may respond to grazers by forming colonies or becoming less colonial may depend on the most dominant grazer (Long et al., 2007). For instance, enhanced colony formation took place when Phaeocystis was exposed to chemical cues from the ciliate Euplotes sp., which consumes smaller particles, while colony suppression in Phaeocystis occurred when it was exposed to chemical signals from the copepod Acartia tonsa Dana that consumes larger particles (Long et al., 2007).

Copepod-induced breakup of chains in the chainforming dinoflagellate Alexandrium tamarense (Lebour) Balech into single cells and reduced swimming speed allowed the dinoflagellates entering a "stealth mode" that lowered encounter rates with copepod grazers (Selander et al., 2011). Dinoflagellates may also produce a bioluminescence flash in response to copepods (Lindström et al., 2017), which leads to near complete rejection of dinoflagellates and with copepods that switch to alternative prey (Prevett et al., 2019). Despite these bioluminescent dinoflagellates 
grow at one-third the rate of their competitors of equivalent size, their defense reduces losses to zooplankton grazers to such extent that they persist in the community (Prevett et al., 2019).

The dinoflagellate Alexandrium minutum Halim responded to polar lipids excreted from copepods with up to a 20-fold increase in the production of saxitoxins that intoxicate copepods (Selander et al., 2015). Although one would expect elevated metabolic costs involved in toxin production, up to date such costs have not been detected (e.g., Tillmann et al., 2009). Possibly, costs will only show up under less nutrientenriched conditions (Pančić \& Kiørboe, 2018). Chemical defenses, such as use of deterrents or toxicity, are also found in cyanobacteria (DeMott \& Moxter, 1991). For instance, Microcystis strains produce numerous compounds that are detrimental to zooplankton, among them a class of heptapeptides-microcystins. Some studies reported that exposure to zooplankton or to cell extracts and microcystins elevated the microcystin content in remaining cells (Jang et al., 2003, 2007; Schatz et al., 2007). These microcystins are toxic to zooplankton and cues related to it can be used by selectively feeding zooplankton to avoid ingestion (Ger et al., 2016), which caused those grazers to switch to alternative non-toxic prey therewith alleviating competition for Microcystis (Ger et al., 2019). Comparison between a microcystin producing wild-type and a microcystin-free mutant strain of $M$. aeruginosa indicated metabolic costs associated with the production of this cyanobacterial toxin (Briand et al., 2012). Dinoflagellates and cyanobacteria generally have lower growth rates than their competitors. They show a widespread ability to respond adaptively to grazers or grazing-associated cues, whereas their mobility (dinoflagellates) or buoyancy control (cyanobacteria) prevent them sinking out of the euphotic zone. Clearly, these organisms have adopted strategies to cope with the major phytoplankton loss processes operating-grazing and sedimentation (Reynolds, 1984; Smetacek, 2001).

From the above it becomes evident that there is a clear trade-off between the costs and benefits of defenses. Those defenses can always be present, or activated only when needed. For example, the colonial green alga Desmodesmus quadricauda (Turpin) Brébisson was classified as permanently defended (Verschoor et al., 2007), whereas Desmodesmus subspicatus (Chodat) E. Hegewald \& A.W.F. Schmidt showed an inducible defense, i.e., it formed colonies when confronted with a grazer, but otherwise remained unicellular (Hessen \& Van Donk, 1993). This grazer-Desmodesmus/Scenedesmus interaction is perhaps the best studied model system on inducible defenses in phytoplankton.

\section{Grazer-induced colony formation}

Hessen \& Van Donk (1993) discovered that when they exposed unicellular D. subspicatus (at that time Scenedesmus subspicatus) to water in which the grazer Daphnia had been present, or to one live Daphnia, the algae rapidly formed colonies within $48 \mathrm{~h}$. Desmodesmus subspicatus increased in size from $8 \times 5 \mu \mathrm{m}$ (length $\times$ width) in unicells to $40 \times 6 \mu \mathrm{m}$ in 8 -celled colonies, with more and rigid spines. Confronted with a high proportion of 8-celled D. subspicatus colonies, grazing of a $1.75 \mathrm{~mm}$ Daphnia was reduced by $75 \%$ reflecting an increased grazing resistance of the colonies (Hessen \& Van Donk, 1993). Research in the decade following upon this discovery yielded more insight in the spread of the response among members of the family Scenedesmaceae, on costs (higher sedimentation rate) and benefits (lower grazing mortality), and further underpinned induced colony formation is an adaptive response to zooplankton grazers caused by a chemical cue (Lürling, 2003a).

More recent research elucidated the chemical nature of the cues involved, which were identified as aliphatic sulfates and sulfamates (Yasumoto et al., 2005, 2006, 2008a, b). These so-called kairomones show strong structural similarity with synthetic anionic surfactants. Two commercially available anionic surfactants (sodium dodecyl sulfate and FFD-6) evoked a similar formation of colonies in Scenedesmus as the natural cues (Lürling, 2012). The morphological response occurred at concentrations far below those that inhibited growth, a traditional endpoint in ecotoxicology, and drastically reduced the clearance rate of Daphnia (Lürling et al., 2011). Such distortion of the adaptive response by pollutants may have consequences for population dynamics of both species in the interaction, but could also be spread out in the ecosystem through numerous biological interactions (Hanazato, 1999). 
The molecular processes behind the response of $D$. subspicatus to produce colonies and form aggregates as an adaptive response to Daphnia cues have been unraveled recently (Roccuzzo et al., 2020). These authors identified a role of the mitogen-activated protein kinase (MAPK) phosphatases signaling pathway in the response of $D$. subspicatus to Daphnia infochemicals. MAPK is triggering cell division and colony formation (Fig. 2). Investments into fatty acid metabolism were also needed for colony formation. Cell-cell adhesion was stimulated by the export of carbohydrates and proteins with disulfide bonds in the extracellular polymeric substances matrix, which also contained fatty acids, a known class of feeding deterrents (Roccuzzo et al., 2020; Fig. 2).

Meanwhile, colony formation in response to zooplankton has been observed in several freshwater green algae, such as Actinastrum, Chlamydomonas, Chlorella, Coelastrum, Desmodesmus, and Scenedesmus (Boraas et al., 1998; Van Donk et al., 1999; Yasumoto et al., 2000; Lürling, 2003a; Fisher et al., 2016), but also in the cyanobacteria Microcystis (e.g., Yang \& Kong, 2012) and Aphanizomenon (Lynch, 1980), and in the marine haptophyte Phaeocystis (Jakobsen \& Tang, 2002; Tang et al., 2008). Hence, induced colony formation seems widespread in phytoplankton. As indicated before, a change in morphological appearance, such as unicellular or colonial, may be a result of both phenotypic plasticity or rapid evolution. For instance, the colonial appearance of $C$. vulgaris in presence of the phagotrophic flagellate predator Ochromonas (Boraas et al., 1998) or when exposed to the rotifer Brachionus, was caused by rapid evolution. Intriguing is that certain species, such as the green alga Chlamydomonas reinhardtii P.A. Dangeard, may form either inducible defensive colonies (palmelloids) against rotifer grazing (Lürling \& Beekman, 2006), or heritable constitutive palmelloids (Becks et al., 2010). Both rapid evolution and phenotypic plasticity occur because of the trade-off between phytoplankton competitive abilities and defenses against grazing. Those adaptive trait changes in prey organisms have the potential to influence population and community dynamics.

\section{Consequences of phytoplankton defenses for population and community dynamics}

In a scenario where grazers and undefended algae are co-cultured, strong population fluctuations will occur. First, due to high phytoplankton growth rates,

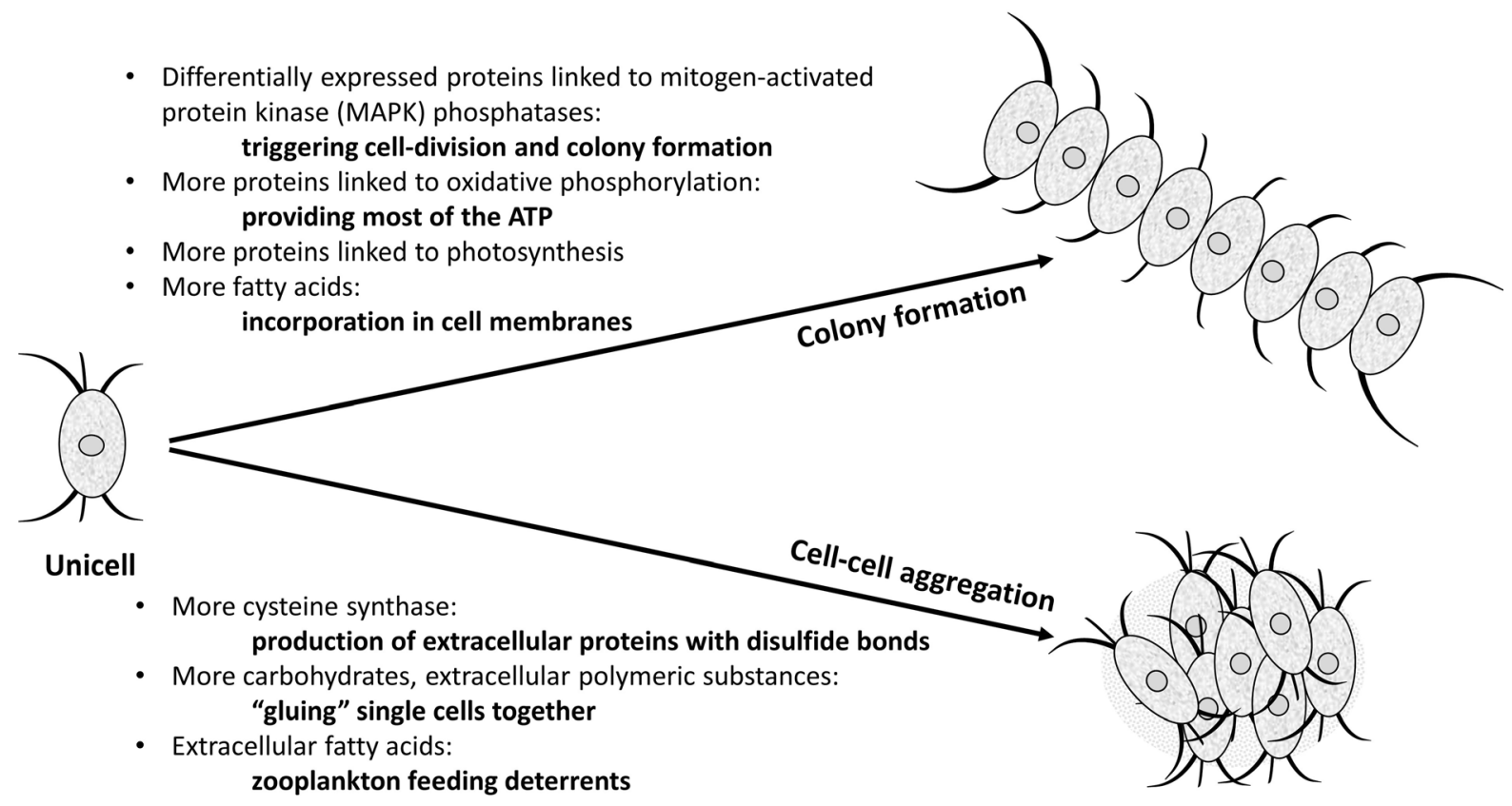

Fig. 2 Overview of the molecular processes in two anti-grazer defense responses: colony formation and cell-cell adhesion: in the green alga Desmodesmus subspicatus (cf. Roccuzzo et al., 2020) 
phytoplankton biomass will strongly increase, but as they are heavily preyed upon, it will be followed by a strong increase in the grazer leading to high grazer densities and low phytoplankton biomass (Fig. 3A). Generally, grazer (predator) oscillations lag behind phytoplankton (prey) oscillations by a quarter of the period (Cortez, 2011). A fixed defense in phytoplankton may reduce the oscillations, or when the phytoplankton cells become virtually inedible, the grazer population may collapse (Fig. 3B). In case of fast, inducible defenses, theory predicts that they promote stability in the phytoplankton-grazer system (Fig. 3C; Cortez, 2011). In contrast, rapid evolution, or quickly evolving traits can desynchronize cycles and increase the lag between the phytoplankton and grazer
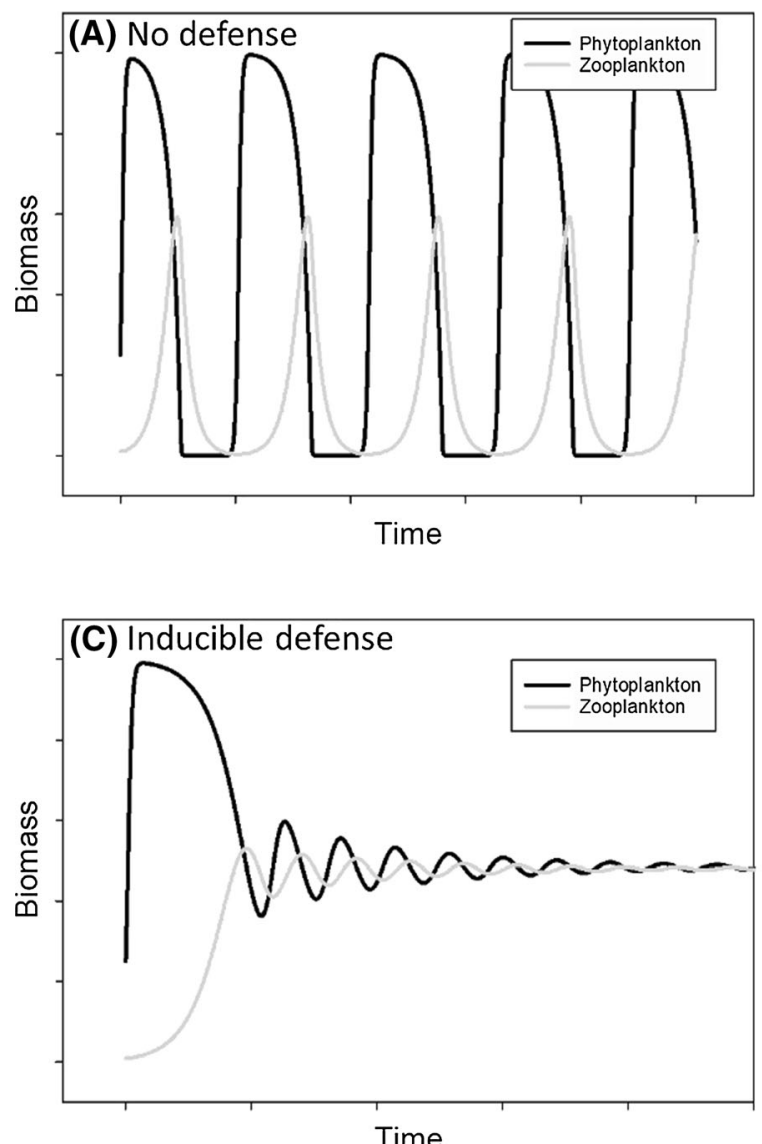

Fig. 3 Theoretical predator-prey cycles in co-cultures of a grazer (for instance the rotifer Brachionus) with undefended phytoplankton (e.g., Selenastrum capricornutum Printz; Panel A), with permanent defended phytoplankton (e.g., Desmodesmus quadricauda; Panel B) - the inset reflects a condition with completely inedible phytoplankton causing extinction of oscillations (Fig. 3D; Cortez, 2011). Indeed, all such patterns have been observed in experiments (Yoshida et al., 2003, 2004, 2007; Verschoor et al., 2004; Lürling et al., 2005; Lürling \& Beekman, 2006; Meyer et al., 2006; Van der Stap et al., 2006, 2009; Becks et al., 2010; Kasada et al., 2014).

In experiments in which an undefended strain of $D$. subspicatus was co-cultured with the rotifer Brachionus calyciflorus Pallas, strong populations fluctuations occurred, but those fluctuations were absent in co-cultures with either inducible defended Scenedesmus obliquus (Turpin) Kützing or permanently defended Desmodesmus quadricauda (Van der Stap et al., 2006). The rotifer went extinct in all replicates with large permanently defended D. quadricauda
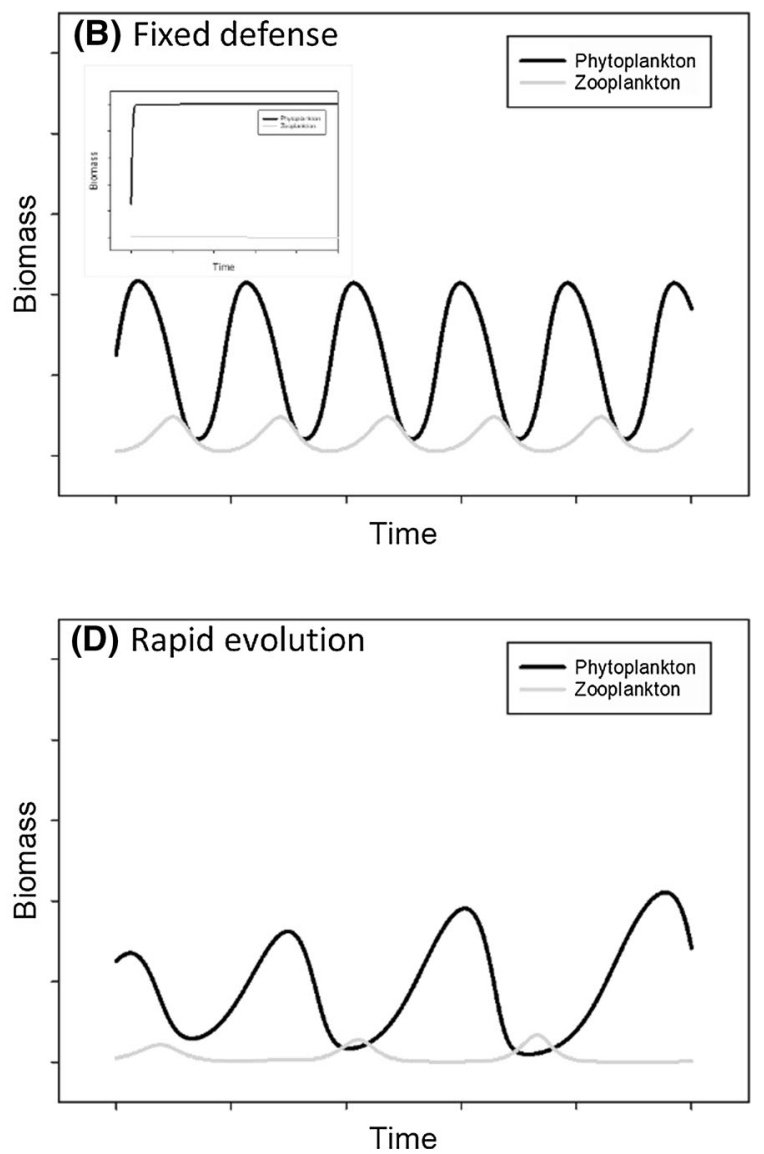

the grazer, with inducible defended phytoplankton (e.g., Scenedesmus obliquus, Chlamydomonas reinhardtii; Panel C), and rapidly evolving phytoplankton (e.g., Chlorella vulgaris, Chlamydomonas reinhardtii; Panel D). Based on chemostat studies and modeling studies (see text) 
(Van der Stap et al., 2006). In chemostat systems with undefended Desmodesmus bicellularis (Chodat) S.S. An, T. Friedl \& E. Hegewald and rotifer Brachionus calyciflorus strong population fluctuations that spanned several orders of magnitude were observed, while these were strongly dampened when Brachionus was co-cultured with the inducible defended $S$. obliquus (Verschoor et al., 2004). The stabilization also occurred when the experiment was run with tritrophic food chains including the predator Asplanchna (Verschoor et al., 2004). Stabilization of intrinsic oscillations was also observed in other Brachionus-Scenedesmus systems, where the induced defense in S. obliquus resulted in more algal biomass and reduced zooplankton growth (Lürling et al., 2005). A similar result was obtained with the green alga Chlamydomonas reinhardtii that formed defensive palmelloid colonies in the presence of rotifers (Lürling \& Beekman, 2006; Becks et al., 2010). In chemostats with permanently defended Desmodesmus quadricauda, the rotifer densities remained very low regardless dilution rate, while these were much higher when grown with inducible defended Scenedesmus obliquus (Van der Stap et al., 2009). In those systems, the phytoplankton-rotifer dynamics did not follow expected limit cycles and phase shift between phytoplankton and rotifer oscillations (Van der Stap et al., 2009). The latter might point towards 'cryptic cycles' that may occur when phytoplankton cells vary genetically for defense traits, which are effective, but not costly (Yoshida et al., 2007).

Single-clone cultures of Chlorella vulgaris (without genetic variability) grown together with Brachionus produced typical short-cycle oscillations with quarter-period phase lags, whereas multi-clonal $C$. vulgaris (with genetic variability) produced long cycles with phytoplankton and rotifer densities nearly out of phase, as theoretically predicted (Yoshida et al., 2003). C. vulgaris cultivated together with rotifers became heritably smaller and competitively inferior relative to $C$. vulgaris grown in the absence of rotifers. Hence, there was a trade-off between grazing resistance and competitive ability among the $C$. vulgaris clones (Yoshida et al., 2003). Meyer et al. (2006) further elaborated on this using the clonal pair UTEX265 (defense) and UTEX396 (undefended) that possessed a trade-off between competitive ability and resistance to grazing. Using an allele-specific quantitative PCR technique these authors showed that the superior competitor UTEX396 dominated initially, but as rotifer densities increased, the grazing-resistant clone UTEX265 became dominant. These two clones have a relatively "cheap defense" trade-off, which means that the defense is effective, but the loss in competitive capacity, expressed in growth rate, is relatively small (Kasada et al., 2014). In contrast, the clones UTEX1809 (undefended) and UTEX1811 (defended) have a relatively "costly defense" tradeoff, which means the defense is not very effective despite a strong reduction in growth rate (Kasada et al., 2014). When mixtures of these two pairs of clones were co-cultured with Brachionus, the relatively high cost of a weak defense favored the undefended clone in the UTEX1809/1811 pair, whereas the defended clone became dominant, or both clones coexisted, for the cheap defense trade-off pair UTEX265/396 (Kasada et al., 2014). Based on the trade-offs between phytoplankton growth and defense against grazing, Yamamichi \& Miner (2015) illustrated in a mathematical model that adaptive evolution of the prey may rescue the predator from extinction.

Despite results from chemostats and models may be difficult to extrapolate to aquatic ecosystems, because most natural planktic systems are not steady state systems (Harris, 1986), they are powerful to yield insight in mechanisms that may steer population dynamics and species interactions and can be used to evaluate observed patterns. In temperate freshwater lakes, a typical sequence of events may be noted, as exemplified from Lake Gødstrup (Denmark) that showed a spring bloom of diatoms was grazed down effectively by Daphnia where after grazing-resistant Aphanizomenon flourished until summer storms introduced nutrients that promoted fast-growing, smallsized cryptomonads (Jacobsen \& Simonsen, 1993). Likewise, in Lake Constance (Germany) highly repetitive annual patterns of fast-growing, edible phytoplankton in spring is followed by strong grazing pressure and subsequent promotion of defended phytoplankton (Ehrlich \& Gaedke, 2020; Ehrlich et al., 2020). The sequence of events is summarized in the PEG model, which reflects biomass patterns of phyto- and zooplankton, but does not zoom in on species replacements (Sommer et al., 2012). Evidently, mixing, competition, grazing by protists and metazoan zooplankton, and parasitism will have an impact on phytoplankton species composition and on the genetic composition of species. 
In the example of Lake Constance, the spring dominance of fast-growing, well-edible phytoplankton species was possible because the grazer community was forced towards small-bodied protist grazers (mostly ciliates) that were controlled by small carnivores (cyclopoid copepods). When large-bodied grazers (Daphnia) appeared the edible phytoplankton community was grazed down rapidly favoring grazing-resistant phytoplankton species, while the carnivore community shifted towards larger carnivorous cladocerans reducing the grazers (Ehrlich \& Gaedke, 2020). This study demonstrated that the trait dynamics were 'primarily endogenously driven by competition and trophic interactions' (Ehrlich \& Gaedke, 2020). It underpins that the CSR model, which is based on the physical structure of the environment (Reynolds, 1993; Smayda \& Reynolds, 2001), should be extended with grazing pressure (Fig. 4).

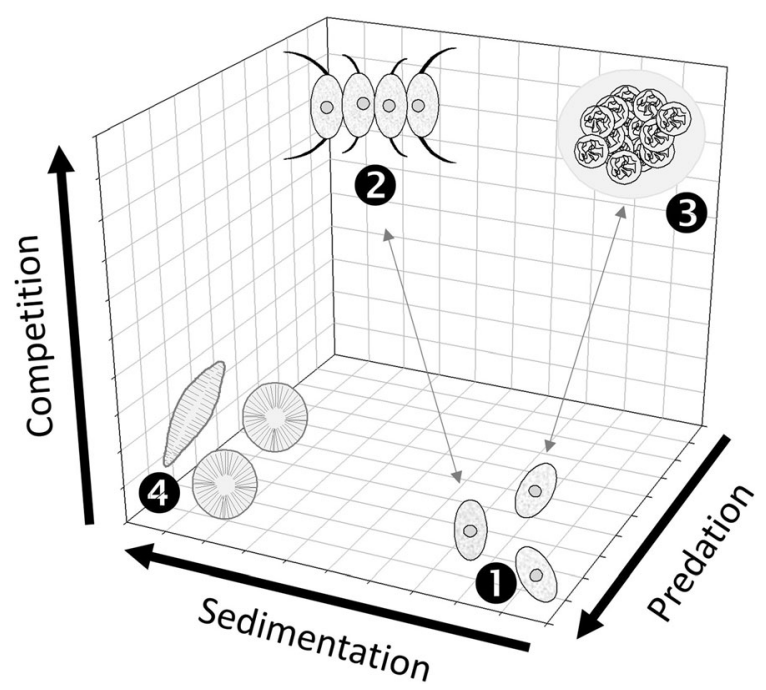

Fig. 4 Three selection forces operating on phytoplankton in the pelagic. Predation is generally largest on small-sized phytoplankton. Sedimentation is usually highest for large cells, colonies, and aggregates that have no buoyancy control, and small cells that have rather high specific mass (diatoms). Competition is mostly strongest on larger cells and colonies that have a less favorable surface-to-volume ratio, and thus lower growth rates. Consequently, small-celled, fast-growing cells suffer most from predation (1) but have in general low sinking loss, and because of favorable surface-to-volume ratio generally experiences less competition. Diatoms can only prevail in a mixed water column (4). Large, sometimes armored cells or colonies have lower growth rates, experience higher sinking rates, but are protected against grazing (2). Some of the slowgrowing colonies or filaments possess the capacity of buoyancy control. The gray arrows indicate potential phenotypic plasticity
Co-evolution of zooplankton grazers to sizes that would allow them to ingest even the largest phytoplankton cells, colonies, and aggregates is strongly constrained as zooplankton themselves are on the menu of visually hunting predators (Lass \& Spaak, 2003; Sommer et al., 2012). Even short-term fish predation events may lead to longer-term reduction in large-bodied grazers (Ersoy et al., 2019). Visually, hunting fish may induce several defenses in zooplankton too, such as Daphnia becoming smaller (Lass \& Spaak, 2003), where smaller animals also have a lower maximum size of particles they can ingest (Burns, 1968).

\section{Concluding remarks}

In the pelagic arena, grazing is one of the most important losses of phytoplankton biomass and thus a very strong selection force for traits that lower grazing losses (Sterner, 1989). It is not surprising that various constitutive or inducible defense strategies in phytoplankton have evolved-avoiding ingestion, avoiding digestion, deterring grazers or even killing zooplankton (Fig. 1). However, cells are also challenged to remain suspended and to cope with competitors. There is ample evidence that the conflicting allometries of selection pressures (Lehman, 1988)—competition that favors small, fast-growing cells with high nutrient uptake and low sinking losses, and grazing that favors large, or defended, slower growing organisms with higher sinking loss-drive the size and shape diversity of phytoplankton (Acevedo-Trejos et al., 2018). It is the whole suite of environmental factors that constrains survival and growth of phytoplankton and confronts cells with trade-offs in how to respond to the constraints (Tilman, 1990).

These trade-offs form the basis for different strategies, which are adopted by representatives of all taxonomic groups. Small size, competitively superior phytoplankton of less than $2 \mu \mathrm{m}$ is, for example, found in diatoms (e.g., Discostella, Cyclotella), in green algae (Choricystis, Pseudodictyosphaerium), in cyanobacteria (Prochlorococcus, Synechococcus), but these groups also include very large, grazingresistant phytoplankton of more than $1 \mathrm{~mm}$ in size (diatom Ethmodiscus, green alga Volvox, cyanobacterium Microcystis). These morphologies determine how the organisms cope with nutrient acquisition, 
sinking and grazing, which formed the basis for the functional group concept (Reynolds et al., 2002). In addition to being very different and avoiding competition, being sufficiently similar has also been proposed as a feasible strategy (Scheffer \& van Nes, 2006), which finds support in the outcome of a recent competition experiment (Burson et al., 2018).

Based on traits, Ehrlich et al. (2020) clustered 199 different phytoplankton species in Lake Constance into 36 dominant morphotypes and found a clear tradeoff between defense and growth rate. Using 21 years of measurements in Lake Constance, a concave defense-growth trade-off was found, in which seasonally increasing grazing pressure shifted the phytoplankton community to higher defense levels at the cost of lower growth rates (Ehrlich et al., 2020). Hence, these authors showed that defense and growth rate represent key traits of the phytoplankton in Lake Constance with changes that were fast enough to prevent competitive exclusion. Using an interspecific defense-growth trade-off, Ehrlich et al. (2020) increased the understanding of seasonal shifts in the species composition of the phytoplankton community. Not only insight in species replacements, but also in genetic shifts within species is needed. While the defense-growth trade-off might be helpful in understanding the development of a cyanobacterial bloom in response to grazing pressure, it will not elucidate whether the bloom will be dominated by toxic or nontoxic genotypes. Future research could be directed into intraspecific, genotype variability along the trade-off curve between competitive ability and defense against grazers.

Resuming, in the pelagic one could imagine adaptive trade-offs between nutrient acquisition (competition), remaining suspended (sedimentation) and grazing resistance (predation) that generate the dynamic phytoplankton composition (Fig. 4). In that view, phytoplankton communities not only "...should be regarded not as the menu, but as the unserved portion of the meal" (Reynolds, 1980), but, besides unserved, also as the mostly inedible left-overs of the meal. Grazing resistance in phytoplankton seems a widespread phenomenon and a key trait in shaping phytoplankton community diversity and species replacements.
Acknowledgements I cordially thank the reviewers and handling editor for their constructive comments and suggestions.

Open Access This article is licensed under a Creative Commons Attribution 4.0 International License, which permits use, sharing, adaptation, distribution and reproduction in any medium or format, as long as you give appropriate credit to the original author(s) and the source, provide a link to the Creative Commons licence, and indicate if changes were made. The images or other third party material in this article are included in the article's Creative Commons licence, unless indicated otherwise in a credit line to the material. If material is not included in the article's Creative Commons licence and your intended use is not permitted by statutory regulation or exceeds the permitted use, you will need to obtain permission directly from the copyright holder. To view a copy of this licence, visit http://creativecommons.org/licenses/by/4.0/.

\section{References}

Acevedo-Trejos, E., E. Marañón \& A. Merico, 2018. Phytoplankton size diversity and ecosystem function relationships across oceanic regions. Proceedings of the Royal Society of London Series B: Biological Sciences 285: 20180621.

Albini, D., M. S. Fowler, C. Llewellyn \& K. W. Tang, 2019. Reversible colony formation and the associated costs in Scenedesmus obliquus. Journal of Plankton Research 41: 419-429.

Becks, L., S. P. Ellner, L. E. Jones \& N. G. Hairston Jr., 2010. Reduction of adaptive genetic diversity radically alters eco-evolutionary community dynamics. Ecology Letters 13: 989-997.

Boraas, M. E., D. B. Seale \& J. E. Boxhorn, 1998. Phagotrophy by a flagellate selects for colonial prey: a possible origin of multicellularity. Evolutionary Ecology 12: 153-164.

Briand, E., M. Bormans, C. Quiblier, M. J. Salençon \& J. F. Humbert, 2012. Evidence of the cost of the production of microcystins by Microcystis aeruginosa under differing light and nitrate environmental conditions. PLoS ONE 7: e29981.

Burns, C. W., 1968. The relationship between body size of filterfeeding Cladocera and the maximum size of particle ingested. Limnology and Oceanography 13: 675-678.

Burson, A., M. Stomp, E. Greenwell, J. Grosse \& J. Huisman, 2018. Competition for nutrients and light: testing advances in resource competition with a natural phytoplankton community. Ecology 99: 1108-1118.

Cerbin, S., L. Wejnerowski \& M. Dziuba, 2013. Aphanizomenon gracile increases in width in the presence of Daphnia. A defence mechanism against grazing? Journal of Limnology 72: 505-511.

Cortez, M. H., 2011. Comparing the qualitatively different effects rapidly evolving and rapidly induced defences have on predator-prey interactions. Ecology Letters 14: 202-209. 
DeMott, W. R., 1999. Foraging strategies and growth inhibition in five daphnids feeding on mixtures of a toxic cyanobacterium and a green alga. Freshwater Biology 42: 263-274.

DeMott, W. R. \& F. Moxter, 1991. Foraging on cyanobacteria by copepods: responses to chemical defenses and resource abundance. Ecology 72: 1820-1834.

DeMott, W. R. \& E. N. McKinney, 2015. Use it or lose it? Loss of grazing defenses during laboratory culture of the digestion-resistant green alga Oocystis. Journal of Plankton Research 37: 399-408.

DeMott, W. R., E. N. McKinney \& A. J. Tessier, 2010. Ontogeny of digestion in Daphnia: implications for the effectiveness of algal defenses. Ecology 91: 540-548.

Ehrlich, E. \& U. Gaedke, 2020. Coupled changes in traits and biomasses cascading through a tritrophic plankton food web. Limnology and Oceanography. https://doi.org/10. 1002/lno.11466.

Ehrlich, E., N. J. Kath \& U. Gaedke, 2020. The shape of a defense-growth trade-off governs seasonal trait dynamics in natural phytoplankton. The ISME Journal 14: 1451-1462.

Ersoy, Z., S. Brucet, M. Bartrons \& T. Mehner, 2019. Short-term fish predation destroys resilience of zooplankton communities and prevents recovery of phytoplankton control by zooplankton grazing. PLoS ONE 14: e0212351.

Fisher, R. M., T. Bell \& S. A. West, 2016. Multicellular group formation in response to predators in the alga Chlorella vulgaris. Journal of Evolutionary Biology 29: 551-559.

Fulton III, R. S. \& H. W. Paerl, 1987. Effects of colonial morphology on zooplankton utilization of algal resources during blue-green algal (Microcystis aeruginosa) blooms. Limnology and Oceanography 32: 634-644.

Fulton III, R. S. \& H. W. Paerl, 1988. Zooplankton feeding selectivity for unicellular and colonial Microcystis aeruginosa. Bulletin of Marine Science 43: 500-508.

Ger, K. A., E. J. Faassen, M. G. Pennino \& M. Lürling, 2016. Effect of the toxin (microcystin) content of Microcystis on copepod grazing. Harmful Algae 52: 34-45.

Ger, K. A., S. Naus-Wiezer, L. De Meester \& M. Lürling, 2019. Zooplankton grazing selectivity regulates herbivory and dominance of toxic phytoplankton over multiple prey generations. Limnology and Oceanography 64: 1214-1227.

Gliwicz, Z. M., 1990a. Daphnia growth at different concentrations of blue-green filaments. Archiv für Hydrobiologie 120: 51-65.

Gliwicz, Z. M., 1990b. Food thresholds and body size in cladocerans. Nature 343: 638-640.

Hanazato, T., 1999. Anthropogenic chemicals (insecticides) disturb natural organic chemical communication in the plankton community. Environmental Pollution 105: 137-142.

Hansson, L. A., 1996. Behavioural response in plants: adjustment in algal recruitment induced by herbivores. Proceedings of the Royal Society of London Series B: Biological Sciences 263: 1241-1244.

Harke, M., M. Steffen, C. Gobler, T. Otten, S. Wilhelm, S. A. Wood \& H. Pearl, 2016. A review of the global ecology, genomics, and biogeography of the toxic cyanobacterium, Microcystis. Harmful Algae 54: 4-20.
Harris, G. P., 1986. Phytoplankton Ecology., Structure, Function and Fluctuation Springer, Dordrecht.

Harvey, E. L. \& S. Menden-Deuer, 2012. Predator-induced fleeing behaviors in phytoplankton: a new mechanism for harmful algal bloom formation? PLoS One 7: e46438.

Hessen, D. O. \& E. Van Donk, 1993. Morphological changes in Scenedesmus induced by substances released from Daphnia. Archiv für Hydrobiologie 127: 129-140.

Jacobsen, B. A. \& P. Simonsen, 1993. Disturbance events affecting phytoplankton biomass, composition and species diversity in a shallow, eutrophic, temperate lake. Hydrobiologia 249: 9-14.

Jakobsen, H. H. \& K. W. Tang, 2002. Effects of protozoan grazing on colony formation in Phaeocystis globosa (Prymnesiophyceae) and the potential costs and benefits. Aquatic Microbial Ecology 27: 261-273.

Jang, M. H., K. Ha, G. E. Joo \& N. Takamura, 2003. Toxin production of cyanobacteria is enhanced by the presence of zooplankton. Freshwater Biology 48: 1540-1550.

Jang, M. H., J. M. Jung \& N. Takamura, 2007. Changes in microcystin production in cyanobacteria exposed to zooplankton at different population densities and infochemical concentrations. Limnology and Oceanography 52: 1454-1466.

Kasada, M., M. Yamamichi \& T. Yoshida, 2014. Form of an evolutionary tradeoff affects eco-evolutionary dynamics in a predator-prey system. Proceedings of the National Academy of Sciences of the United States of America 111: 16035-16040.

Lass, S. \& P. Spaak, 2003. Chemically induced anti-predator defences in plankton: a review. Hydrobiologia 491: 221-239.

Latta IV, L. C., R. P. O’Donnell \& M. E. Pfrender, 2009. Vertical distribution of Chlamydomonas changes in response to grazer and predator kairomones. Oikos 118: 853-858.

Lehman, J. T., 1988. Selective herbivory and its role in the evolution of phytoplankton growth strategies. In Sandgren, C. D. (ed.), Growth and Reproductive Strategies of Freshwater Phytoplankton. Cambridge University Press, New York: 369-387.

Lindström, J., W. Grebner, K. Rigby \& E. Selander, 2017. Effects of predator lipids on dinoflagellate defence mechanisms - increased bioluminescence capacity. Scientific Reports 7: 13104.

Long, J. D., G. W. Smalley, T. Barsby, J. T. Anderson \& M. E. Hay, 2007. Chemical cues induce consumer-specific defenses in a bloom-forming marine phytoplankton. Proceedings of the National Academy of Sciences of the United States of America 104: 10512-10517.

Lürling, M., 2003a. Phenotypic plasticity in the green algae Desmodesmus and Scenedesmus with special reference to the induction of defensive morphology. Annales de Limnologie: International Journal of Limnology 39: 85-101.

Lürling, M., 2003b. Daphnia growth on microcystin-producing and microcystin-free Microcystis aeruginosa in different mixtures with the green alga Scenedesmus obliquus. Limnology and Oceanography 48: 2214-2220.

Lürling, M., 2012. Info-disruption: pollutants interfering with the natural chemical information conveyance in aquatic systems. In Brönmark, C. \& L. A. Hansson (eds), 
Chemically Mediated Interactions in Aquatic Habitats. Oxford University Press, Oxford: 250-271.

Lürling, M. \& W. Beekman, 2006. Palmelloids formation in Chlamydomonas reinhardtii: defence against rotifer predators? Annales de Limnologie: International Journal of Limnology 42: 65-72.

Lürling, M., H. Arends, W. Beekman, M. Vos, I. Van der Stap, W. M. Mooij \& M. Scheffer, 2005. Effect of grazer-induced morphological changes in the green alga Scenedesmus obliquus on growth of the rotifer Brachionus calyciflorus. Internationale Vereinigung für theoretische und angewandte Limnologie: Verhandlungen 29: 698-703.

Lürling, M., H. J. De Lange \& E. T. H. M. Peeters, 2011. Effects of an anionic surfactant (FFD-6) on the energy and information flow between a primary producer (Scenedesmus obliquus) and a consumer (Daphnia magna). Ecotoxicology 20: 1881-1889.

Lynch, M., 1980. Aphanizomenon blooms: alternate control and cultivation by Daphnia pulex. American Society of Limnology and Oceanography Special Symposium 28: 299-304.

Meyer, J. R., S. P. Ellner, N. G. Hairston Jr., L. E. Jones \& T. Yoshida, 2006. Prey evolution on the time scale of predator-prey dynamics revealed by allele-specific quantitative PCR. Proceedings of the National Academy of Sciences of the United States of America 103: 10690-10695.

Pančić, M. \& T. Kiørboe, 2018. Phytoplankton defence mechanisms: traits and trade-offs. Biological Reviews 93: 1269-1303.

Pančić, M., R. R. Torres, R. Almed \& T. Kiørboe, 2019. Silicified cell walls as a defensive trait in diatoms. Proceedings of the Royal Society of London Series B: Biological Sciences 286: 20190184.

Pondaven, P., M. Gallinari, S. Chollet, E. Bucciarelli, G. Sarthou, S. Schultes \& F. Jean, 2007. Grazing-induced changes in cell wall silicification in a marine diatom. Protist 158: 21-28.

Prevett, A., J. Lindström, J. Xu, B. Karlson \& E. Selander, 2019. Grazer-induced bioluminescence gives dinoflagellates a competitive edge. Current Biology 29: R564-R565.

Rengefors, K., I. Karlsson \& L. A. Hansson, 1998. Algal cyst dormancy: a temporal escape from herbivory. Proceedings of the Royal Society of London Series B: Biological Sciences 265: 1353-1358.

Reynolds, C. S., 1980. Phytoplankton assemblages and their periodicity in stratifying lake systems. Holarctic Ecology 3: $141-159$.

Reynolds, C. S., 1984. Phytoplankton periodicity: the interactions of form, function and environmental variability. Freshwater Biology 14: 111-142.

Reynolds, C. S., 1993. Scales of disturbance and their role in plankton ecology. Hydrobiologia 249: 157-171.

Reynolds, C. S., 1998. What factors influence the species composition of phytoplankton in lakes of different trophic status? Hydrobiologia 369(370): 11-26.

Reynolds, C. S., 2006. The Ecology of Phytoplankton. Cambridge University Press, Cambridge.

Reynolds, C. S., 2012. Environmental requirements and habitat preferences of phytoplankton: chance and certainty in species selection. Botanica Marina 55: 1-17
Reynolds, C. S., H. R. Morison \& C. Butterwick, 1982. The sedimentary flux of phytoplankton in the South Basin of Windemere. Limnology and Oceanography 27: 1162-1175.

Reynolds, C. S., V. Huszar, C. Kruk, L. Naselli-Flores \& S. Melo, 2002. Towards a functional classification of the freshwater phytoplankton. Journal of Plankton Research 24: 417-428.

Roccuzzo, S., N. Couto, E. Karunakaran, R. V. Kapoore, T. O. Butler, J. Mukherjee, E. M. Hansson, A. P. Beckerman \& J. Pandhal, 2020. Metabolic insights into infochemicals induced colony formation and flocculation in Scenedesmus subspicatus unraveled by quantitative proteomics. Frontiers in Microbiology 11: 792.

Rothhaupt, K. O., 1990. Population growth rates of two closely related rotifer species: effects of food quantity, particle size and nutritional quality. Freshwater Biology 23: 561-570.

Schatz, D., Y. Keren, A. Vardi, A. Sukenik, S. Carmeli, T. Börner, E. Dittmann \& A. Kaplan, 2007. Towards clarification of the biological role of microcystins, a family of cyanobacterial toxins. Environmental Microbiology 9: 965-970.

Scheffer, M. \& E. H. van Nes, 2006. Self-organized similarity, the evolutionary emergence of groups of similar species. Proceedings of the National Academy of Sciences of the United States of America 103: 6230-6235.

Selander, E., H. H. Jakobsen, F. Lombard \& T. Kiørboe, 2011. Grazer cues induce stealth behavior in marine dinoflagellates. Proceedings of the National Academy of Sciences of the United States of America 108: 4030-4034.

Selander, E., J. Kubanek, M. Hamberg, M. X. Andersson, G. Cervin \& H. Pavia, 2015. Predator lipids induce paralytic shellfish toxins in bloom-forming algae. Proceedings of the National Academy of Sciences of the United States of America 112: 6395-6400.

Smayda, T. J. \& C. S. Reynolds, 2001. Community assembly in marine phytoplankton: application of recent models to harmful dinoflagellate blooms. Journal of Plankton Research 23: 447-461.

Smetacek, V., 2001. A watery arms race. Nature 411: 745.

Sommer, U., Adrian, R., De Senerpont Domis, L., Elser, J. J., Gaedke, U., Ibelings, B., Jeppesen, E., Lürling, M., Molinero, J. C., Mooij, W. M., van Donk, E., Winder, M. (2012) Beyond the Plankton Ecology Group (PEG) model: Mechanisms driving plankton succession. Annual Review of Ecology, Evolution, and Systematics 43(1): 429-448

Sterner, R. W., 1989. The role of grazers in phytoplankton succession. In Sommer, U. (ed.), Plankton Ecology: Succession in Plankton Communities. Springer, Berlin: 107-170.

Tang, K. W., W. O. Smith Jr., D. T. Elliott \& A. R. Shields, 2008. Colony size of Phaeocystis antarctica (Prymnesiophyceae) as influenced by zooplankton grazers. Journal of Phycology 44: 1372-1378.

Tillmann, U., T. L. Alpermann, R. C. da Purificação, B. Krock \& A. Cembella, 2009. Intra-population clonal variability in allelochemical potency of the toxigenic dinoflagellate Alexandrium tamarense. Harmful Algae 8: 759-769.

Tilman, D., 1990. Constraints and tradeoffs: toward a predictive theory of competition and succession. Oikos 58: 3-15. 
Tollrian, R. \& C. D. Harvell, 1999. The Ecology and Evolution of Inducible Defenses. Princeton University Press, Princeton.

van der Stap, I., M. Vos \& W. M. Mooij, 2006. Linking herbivore-induced defences to population dynamics. Freshwater Biology 51: 424-434.

van der Stap, I., M. Vos, B. W. Kooi, B. T. M. Mulling, E. van Donk \& W. M. Mooij, 2009. Algal defenses, population stability, and the risk of herbivore extinctions: a chemostat model and experiment. Ecological Research 24: 1145-1153.

Van Donk, E., M. Lürling, D. O. Hessen \& G. M. Lokhorst, 1997. Altered cell wall morphology in nutrient-deficient phytoplankton and its impact on grazers. Limnology and Oceanography 42: 357-364.

Van Donk, E., M. Lürling \& W. Lampert, 1999. Consumerinduced changes in phytoplankton: inducibility, costs, benefits and impacts on grazers. In Harvell, C. D. \& R. Tollrian (eds), The Ecology and Evolution of Inducible Defenses. Princeton University Press, Princeton: 89-103.

Van Donk, E., A. Ianora \& M. Vos, 2011. Induced defences in marine and freshwater phytoplankton: a review. Hydrobiologia 668: 3-19.

Verschoor, A. M., M. Vos \& I. van der Stap, 2004. Inducible defences prevent strong population fluctuations in bi- and tritrophic food chains. Ecology Letters 7: 1143-1148.

Verschoor, A. M., Y. Zadereev \& W. M. Mooij, 2007. Infochemical-mediated trophic interactions between the rotifer Brachionus calyciflorus and its food algae. Limnology and Oceanography 52: 2109-2119.

Verschoor, A. M., O. K. Bekmezci, E. Van Donk \& J. Vijverberg, 2009. The ghost of herbivory past: slow defence relaxation in the chlorophyte Scenedesmus obliquus. Journal of Limnology 68: 327-335.

Wejnerowski, L., S. Cerbin, M. Wojciechowicz, T. Jurczak, M. Glama, J. Meriluoto \& M. Dziuba, 2018. Effects of Daphnia exudates and sodium octyl sulphates on filament morphology and cell wall thickness of Aphanizomenon gracile (Nostocales), Cylindrospermopsis raciborskii (Nostocales) and Planktothrix agardhii (Oscillatoriales). European Journal of Phycology 53: 280-289.

Xiao, M., A. Willis, M. A. Burford \& M. Li, 2017. Review: a meta-analysis comparing cell-division and cell-adhesion in Microcystis colony formation. Harmful Algae 67: 85-91.

Xiao, M., M. Li \& C. S. Reynolds, 2018. Colony formation in the cyanobacterium Microcystis. Biological Reviews 93: 1399-1420.

Xu, J. \& T. Kiørboe, 2018. Toxic dinoflagellates produce true grazer deterrents. Ecology 99: 2240-2249.

Yamamichi, M. \& B. E. Miner, 2015. Indirect evolutionary rescue: prey adapts, predator avoids extinction. Evolutionary Applications 8: 787-795.

Yamamichi, M., T. Yoshida \& A. Sasaki, 2011. Comparing the effects of rapid evolution and phenotypic plasticity on predator-prey dynamics. The American Naturalist 178: 287-304.
Yang, Z. \& F. Kong, 2012. Formation of large colonies: a defense mechanism of Microcystis aeruginosa under continuous grazing pressure by flagellate Ochromonas sp. Journal of Limnology 71: 61-66.

Yang, Z., F. Kong, Z. Yang, M. Zhang, Y. Yu \& S. Qian, 2009. Benefits and costs of the grazer-induced colony formation in Microcystis aeruginosa. Annales de Limnologie-International Journal of Limnology 45: 203-208.

Yasumoto, M., T. Ooi, K. Takenori \& F. Kasai, 2000. Characterization of Daphnia kairomone inducing morphological change of green alga Actinastrum sp. Tennen Yuki Kagobutsu Toronkai Keon Yoshishu 42: 385-390 (in Japanese).

Yasumoto, K., A. Nishigami, M. Yasumoto, F. Kasai, Y. Okada, T. Kusumi \& T. Ooi, 2005. Aliphatic sulfates released from Daphnia induce morphological defense of phytoplankton: isolation and synthesis of kairomones. Tetrahedron Letters 46: 4765-4767.

Yasumoto, K., A. Nishigami, F. Kasai, T. Kusumi \& T. Ooi, 2006. Isolation and absolute configuration determination of aliphatic sulfates as the Daphnia kairomones inducing morphological defense of a phytoplankton. Chemical and Pharmaceutical Bulletin 54: 271-274.

Yasumoto, K., A. Nishigami, H. Aoi, C. Tsuchihashi, F. Kasai, T. Kusumi \& T. Ooi, 2008a. Isolation and absolute configuration determination of aliphatic sulfates as the Daphnia kairomones inducing morphological defense of a phytoplankton - Part 2. Chemical and Pharmaceutical Bulletin 56: 129-132.

Yasumoto, K., A. Nishigami, H. Aoi, C. Tsuchihashi, F. Kasai, T. Kusumi \& T. Ooi, 2008b. Isolation of new aliphatic sulfates and sulfamate as the Daphnia kairomones inducing morphological change of a phytoplankton Scenedesmus gutwinskii. Chemical and Pharmaceutical Bulletin 56: 133-136.

Yoshida, T., L. E. Jones, S. P. Ellner, G. F. Fussmann \& N. G. Hairston Jr., 2003. Rapid evolution drives ecological dynamics in a predator-prey system. Nature 424: 303-306.

Yoshida, T., N. G. Hairston \& S. P. Ellner, 2004. Evolutionary trade-off between defence against grazing and competitive ability in a simple unicellular alga, Chlorella vulgaris. Proceedings of the Royal Society of London Series B: Biological Sciences 271: 1947-1953.

Yoshida, T., S. P. Ellner, L. E. Jones, B. J. M. Bohannan, R. E. Lenski \& N. G. Hairston Jr., 2007. Cryptic population dynamics: rapid evolution masks trophic interactions. PLoS Biology 5: e235.

Zhu, X., J. Wang, Q. Chen, G. Chen, Y. Huang \& Z. Yang, 2016. Costs and trade-offs of grazer-induced defenses in Scenedesmus under deficient resource. Scientific Reports 6: 22594.

Publisher's Note Springer Nature remains neutral with regard to jurisdictional claims in published maps and institutional affiliations. 